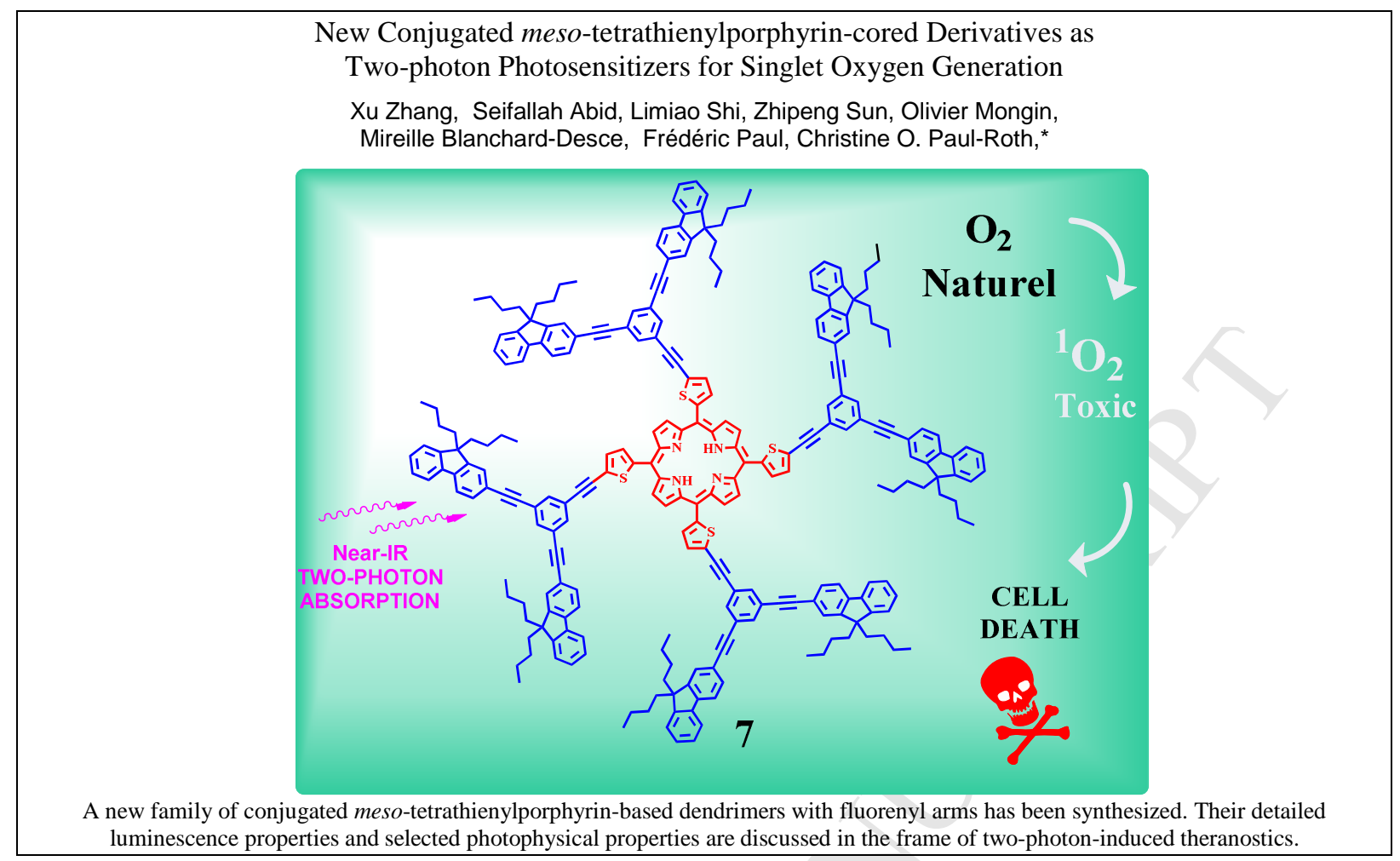

new family of conjugated meso-tetrathienylporphyrin-based dendrimers with fluorenyl arms has been synthesized. Their detailed
luminescence properties and selected photophysical properties are discussed in the frame of two-photon-induced theranostics. 


\title{
New Conjugated meso-Tetra(thien-2-yl)porphyrin-Cored Derivatives as Two-photon Photosensitizers for Singlet Oxygen Generation
}

\author{
Xu Zhang, ${ }^{\mathrm{a}}$ Seifallah Abid, ${ }^{\mathrm{a}, \mathrm{b}}$ Limiao Shi, ${ }^{\mathrm{a}}$ Zhipeng Sun, ${ }^{\mathrm{a}}$ Olivier Mongin, ${ }^{\mathrm{a}}$ \\ Mireille Blanchard-Desce, ${ }^{\mathrm{c}}$ Frédéric Paul, ${ }^{\mathrm{a}}$ Christine O. Paul-Roth, ${ }^{\mathrm{a}}{ }^{\mathrm{a}}$ \\ ${ }^{a}$ Univ Rennes, INSA Rennes, CNRS, ISCR (Institut des Sciences Chimiques de Rennes) - UMR 6226, F-35000 \\ Rennes, France \\ ${ }^{b}$ Université de Carthage, Faculté des Sciences de Bizerte, Tunisie \\ ${ }^{c}$ Université de Bordeaux, Institut des Sciences Moléculaires (CNRS UMR 5255), 33405 Talence, France
}

*Corresponding author: christine.paul@univ-rennes1.fr or christine.paul@insa-rennes.fr tel : (+33) (0) 223236372 fax: (+33) (0) 223236372

\begin{abstract}
A series of conjugated meso-porphyrin dendrimers containing conjugated fluorenyl dendrons, incorporating overall either four (3) or eight (4) fluorenyl units have been synthesized and characterized. These new molecular architectures are based on a central meso-tetra(thien-2yl)porphyrin core (TThP). Their linear optical properties, absorption and photoluminescence, as well as selected nonlinear optical properties, were investigated and compared to those of the unsubstituted meso-(thien-2-yl)porphyrin core (5) and also to those of previously reported analogues featuring 1,4-phenylene groups (1 and 2) in place of 2,5-thienylene moieties. The positive role of these thienylene linkers over phenylene linkers on the two-photon absorption (2PA) cross-sections is clearly evidenced.
\end{abstract}

\section{Keywords}

Tetrathienyl Porphyrin •Fluorenyl •Two-Photon Absorption •Luminescence • Oxygen Sensitization

\section{INTRODUCTION}

Organic molecular materials exhibiting third-order nonlinear optical ( $3^{\text {rd }}$ NLO) properties are used nowadays in a wide range of key societal applications, such as all-optical communication, 
ultra-dense optical data storage or microfabrication. ${ }^{[1]}$ This situation has fostered the extensive development of fundamental studies aimed at understanding and improving the third-order NLO responses of various classes of molecules. Classic $3^{\text {rd }}$ NLO processes used for these applications rest mostly on two types of phenomena: (i) nonlinear refractive effects ${ }^{[2]}$ and (ii) nonlinear absorptive effects, namely two-photon absorption (2PA), reverse saturable absorption (RSA) and saturable absorption (SA). The first of these nonlinear absorptive effects (2PA) deserves some particular attention because it has also fostered tremendous activity in various bio-related fields since the beginning of this century.

For instance, depending on the properties of the excited state populated by biphotonic absorption, specific chromophores have now been developed for important societal tasks such as two-photon fluorescence imaging ${ }^{[1 \mathrm{~b}, 3]}$ or two-photon photodynamic therapy (PDT). ${ }^{[4]}$ Indeed, it is now well established that via 2PA, these effects can be triggered by laser light with much better spatial definition, much deeper penetration in living tissues, and in a much more innocuous way than via traditional one-photon (1PA) excitation using conventional light sources. ${ }^{[1 \mathrm{a}, \mathrm{b}]}$ However there is a growing need to improve further the existing systems or to develop new systems. In this respect, the extensive literature available on third-order properties can be quite usefully used, as we shall show hereafter. ${ }^{[5]}$

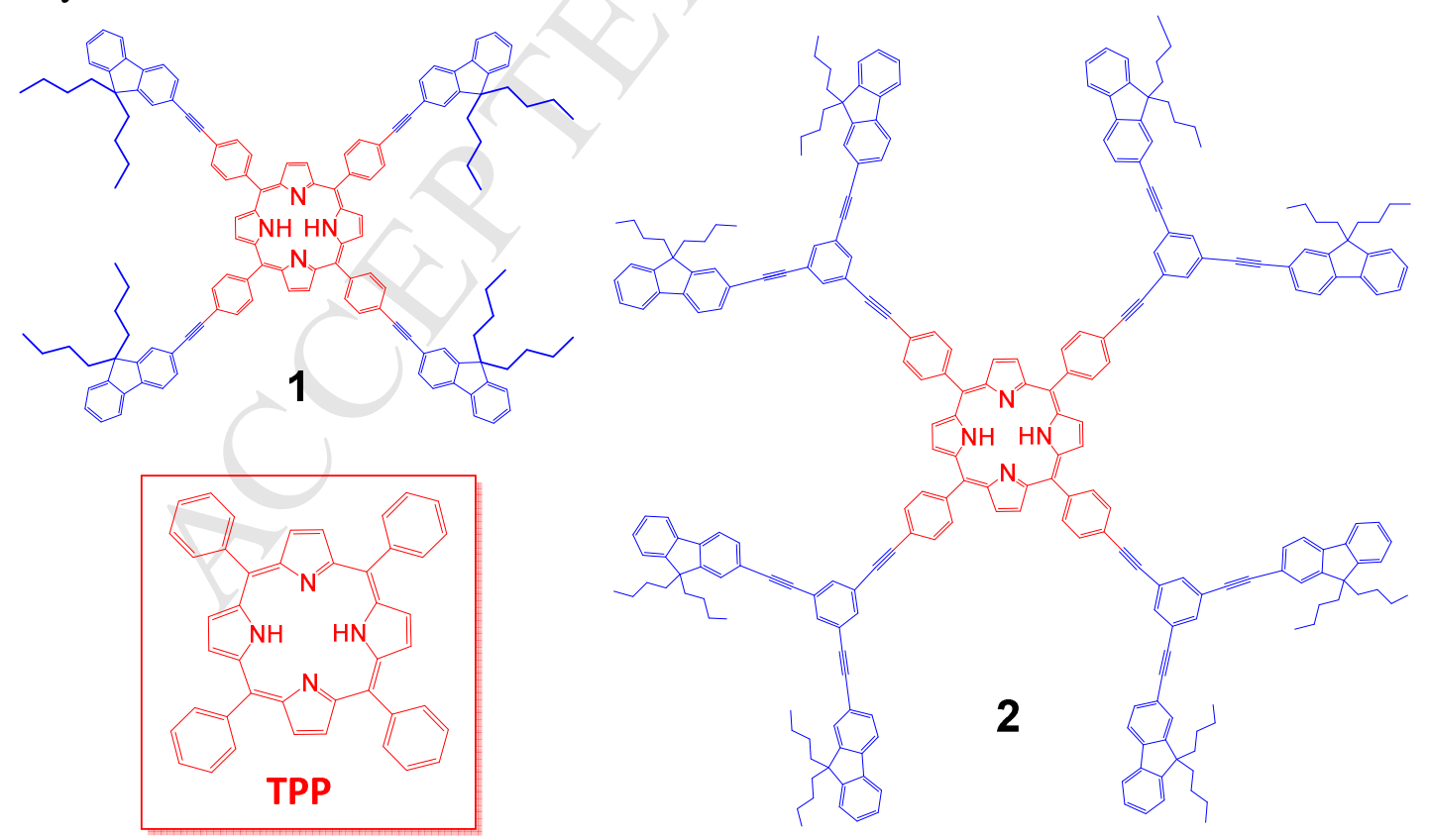


Scheme 1. Meso-tetraphenylporphyrin-based fluorescent oxygen photosensitizers $\mathbf{1}$ and $\mathbf{2}$ and reference TPP.

In the continuation of former studies aimed at identifying molecules for theranostics (i.e. allowing imaging and curing at the same time),${ }^{[6]}$ we have recently reported a series of mesotetraphenylporphyrin-based dendrimers such as $\mathbf{1}$ or $\mathbf{2}$ (Scheme 1). ${ }^{[7]}$ These fluorescent dendrimers were able to efficiently photogenerate singlet oxygen and also turned out to be fair two-photon absorbers, presenting thereby the attractive possibility to develop 2PA-based photosensitizers for theranostics. In order to learn a little more about the potential of this class of molecules, we have now decided to attempt the identification of analogues with improved 2PA capabilities.

As obvious from various examples, ${ }^{[5,8]}$ replacement of a 1,4-phenylene group by a 2,5thienylene group (Scheme 2 ) within a given conjugated $\pi$-manifold while preserving its overall symmetry (A- $\pi$-A or D- $\pi$-D for quadrupoles) results usually in a significant improvement of the 2PA cross-section $\left(\sigma_{2}\right)$. Based on such considerations, replacement of the meso-1,4-phenylene groups by meso-2,5-thienylene group in $\mathbf{1}$ and $\mathbf{2}$ should improve their 2PA cross-sections. We therefore targeted the dendrimers $\mathbf{3}$ and $\mathbf{4}$ (Scheme 2), which are the tetrathienyl analogues of $\mathbf{1}$ and 2 (Scheme 1), respectively, as well as meso-tetra(thien-2-yl)porphyrin TThP (5) which will be used as a reference compound for these studies. The latter compound has been known since $1968^{[9]}$ and was so far mainly prepared using the Alder-Longo method ${ }^{[10]}$ and also by the Lindsey method, ${ }^{[11]}$ the latter approach giving apparently better yields. ${ }^{[12]}$ [Note: We have previously also isolated a porphyrin analogous to TThP via the Lindsey method, but featuring only two meso-thienyl groups in trans positions and two meso-phenyl groups. Unfortunately, the nonlinear optical properties of this molecule were not studied at that time. $\left.{ }^{[13]}\right]$

In contrast to TThP, dendrimers $\mathbf{3}$ and $\mathbf{4}$ are new molecules. However, molecules closely related to $\mathbf{3}$ and $\mathbf{4}$ have also been isolated using the method of Lindsey, ${ }^{[14]}$ suggesting that our targets might also be synthetically accessed via this alternative (and often more productive) approach. 


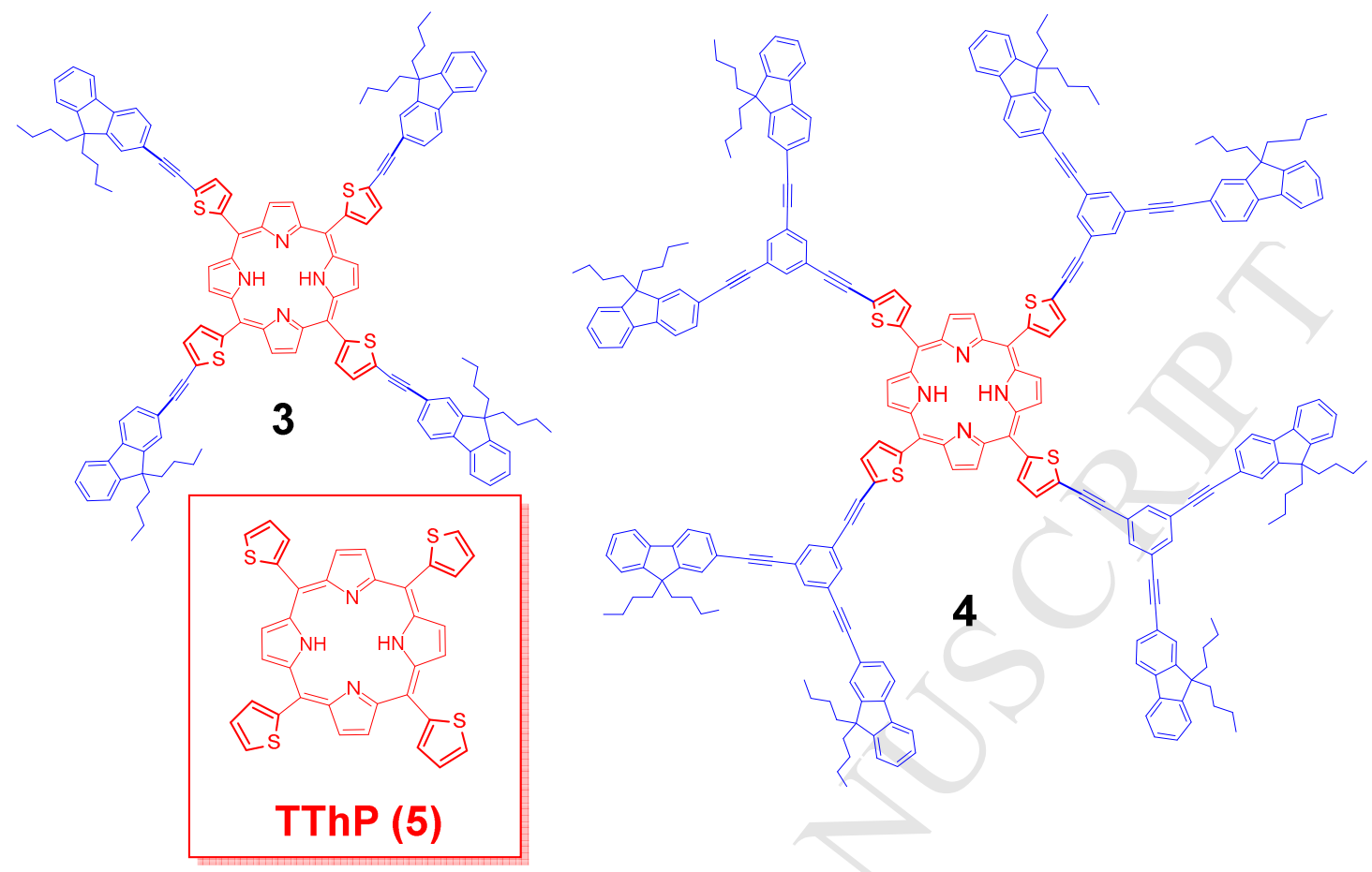

Scheme 2. Targeted meso-tetra(thien-2-yl)porphyrins (3 and 4) and reference meso-tetra(thien-2yl)porphyrin TThP (5).

We thus report in the following the (i) synthesis and full characterization of meso-(2-((9,9dibutylfluoren-2-yl)ethynyl)-thienyl)porphyrin (3) and meso-(2-((3,5-bis((9,9-dibutylfluoren-2yl)ethynyl)phenyl)ethynyl)-thienyl)porphyrin (4) based on a Lindsey protocol ${ }^{[15]}$ for synthesizing the porphyrin core, followed by (ii) the study of their linear and nonlinear photophysical properties of interest in relation to theranostics. Finally, (iii) these properties will be compared to those of $\mathbf{1}$, and $\mathbf{2}$ and the interest of the structural modification for photosensitizing oxygen will be discussed.

\section{RESULTS}

\section{Synthesis of the Dendrimers}

To prepare this new family of porphyrin-based dendrimers, the Lindsey method, ${ }^{[15]}$ Sonogashira couplings ${ }^{[16]}$ and Corey-Fuchs reactions ${ }^{[17]}$ were successively used to access the targeted molecules: 3, $\mathbf{4}$ and reference TThP. In more detail, the strategy adopted basically involves 
three steps; (i) the synthesis of dendrons 6 and 7 (Scheme 3), (ii) the isolation of the tetra-iodo porphyrin precursor $\mathbf{8}$ and, finally, (iii) the formation of the desired porphyrin-based dendrimers 3 and $\mathbf{4}$ in a final step. As previously accomplished, ${ }^{[7,18]} n$-butyl chains were firstly fixed in the 9 position of the fluorenyl unit(s) in order to improve the solubility of the final molecules.

The desired dendrons were obtained via iterative Sonogashira couplings and Corey-Fuchs reactions, based on related chemistry previously developed in our group (Scheme 3). ${ }^{[7,18-19]}$ The isolation of dendron 6 from 2-bromofluorene in a total yield of 74\% was rather straightforward. Dendron 7 was next obtained in $c a$. $63 \%$ total yield after a two-step Corey-Fuchs procedure from the corresponding aldehyde precursor, ${ }^{[19]}$ itself obtained from one equivalent of 3,5dibromobenzaldehyde and two equivalents of dendron $\mathbf{6}$.
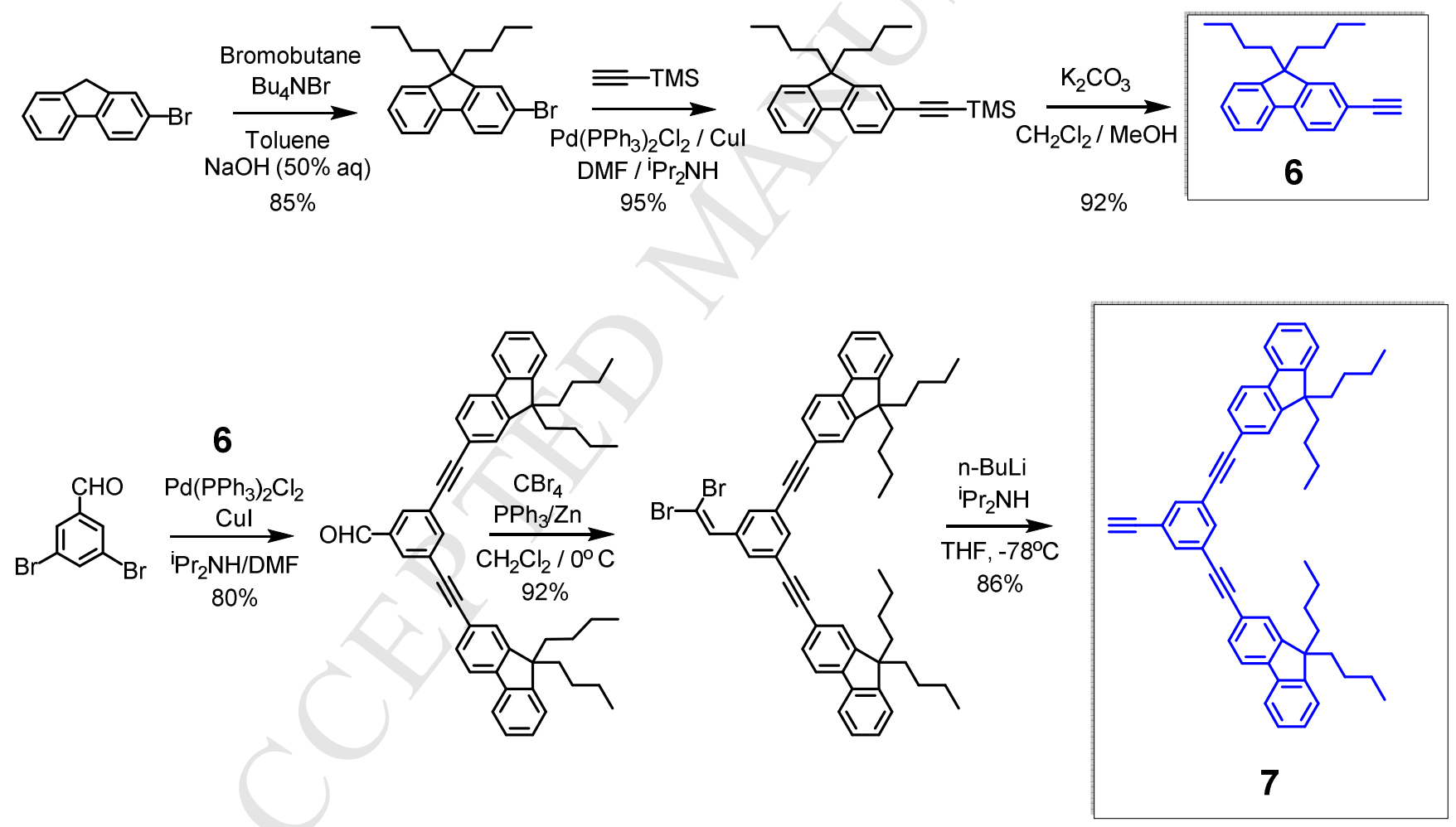

Scheme 3. Synthesis of conjugated dendrons 6 and 7.

The reference compound TThP (5) has been previously isolated following various conditions. ${ }^{[12]}$ Lindsey's conditions ${ }^{[15]}$ were eventually retained to attempt performing its synthesis (Scheme 4) and that from the other required precursor: meso-tetra(5-iodo-thien-2-yl)porphyrin (8). The 
former compound 5 was thus synthesized from 2-thienylcarboxaldehyde and pyrrole in the presence of a Lewis acid $\left(\mathrm{BF}_{3} \cdot \mathrm{OEt}_{2}\right)$, followed by addition of $p$-chloranil as an oxidizer in $32 \%$ yield, while its iodo analogue 8 was similarly isolated in 19\% yield from (5-iodo-thien-2yl)carboxaldehyde. Subsequently, from this precursor (8) and the dendrons 6 and 7, the targeted porphyrin systems 3 and $\mathbf{4}$ were obtained in good yields by Sonogashira coupling reactions ${ }^{[16]}$ (37\% and $40 \%$, resp.).

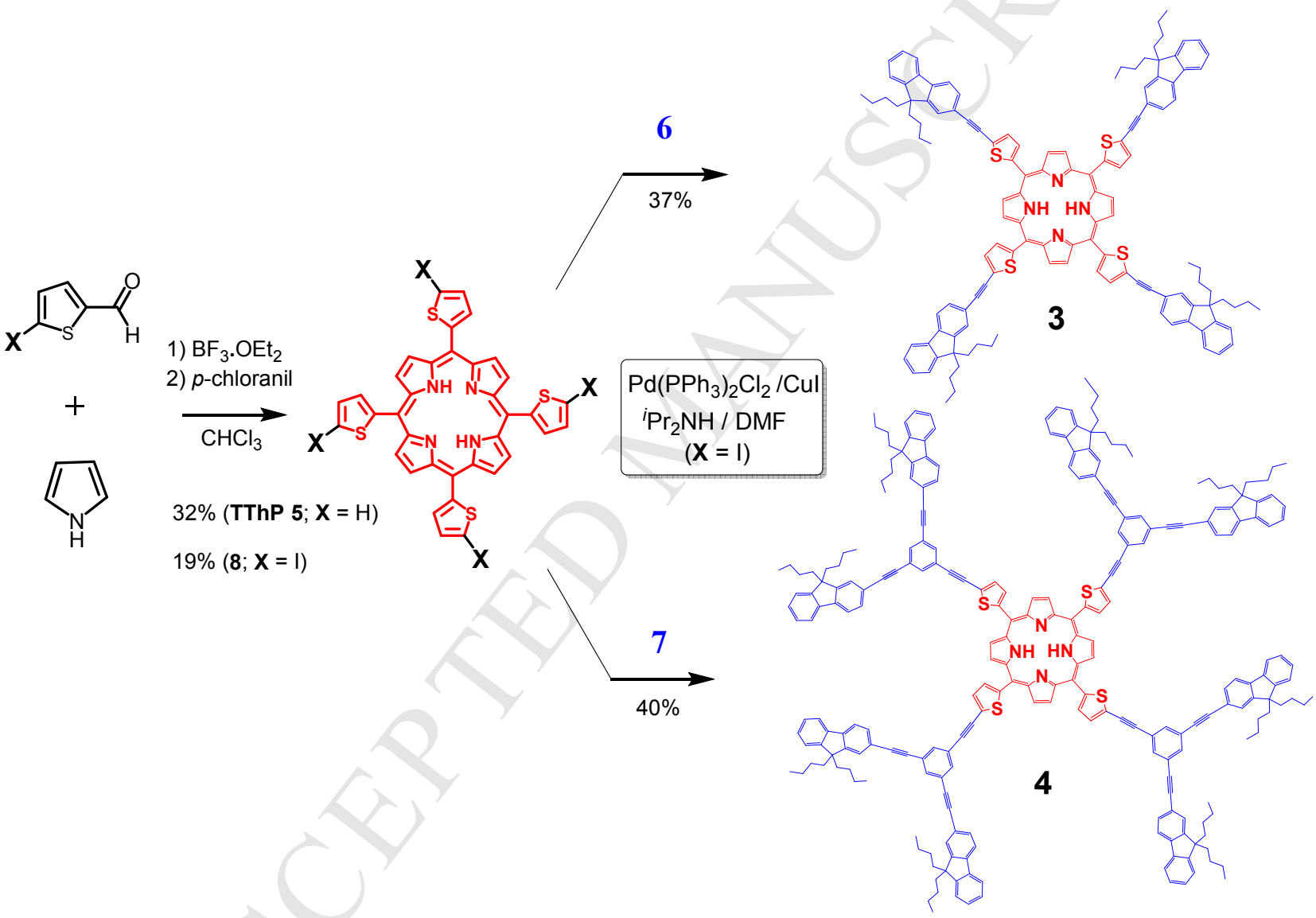

Scheme 4. Syntheses of the reference meso-tetra(thien-2-yl)porphyrin (5), of intermediate meso-tetra(5iodothien-2-yl)porphyrin 8 and the corresponding targeted dendrimers 3 and 4.

\section{${ }^{1}$ H NMR Characterization}

The new porphyrin-based dendrimers $\mathbf{3}$ and $\mathbf{4}$ were characterized by ESI-HRMS, by elemental analysis and by ${ }^{1} \mathrm{H}$ and ${ }^{13} \mathrm{C}$ NMR in $\mathrm{CDCl}_{3}$ (400 and $500 \mathrm{MHz}$, resp.). In both cases the ${ }^{1} \mathrm{H}$ NMR spectrum was very diagnostic (see Figure 1, for compound 3), revealing four groups of peaks: (i) 
eight $\beta$-pyrrolic protons at low fields around $9.2 \mathrm{ppm}$; (ii) aromatic protons belonging to 2,5thienylene bridges, to phenyl linkers and to fluorenyl endgroups (7.3-8.0 ppm); (iii) aliphatic protons belonging to the methyl and methylene parts of the various $n$-butyl chains (0.5-2.1 ppm), and (iv) two NH protons at high fields around -2.6 ppm.

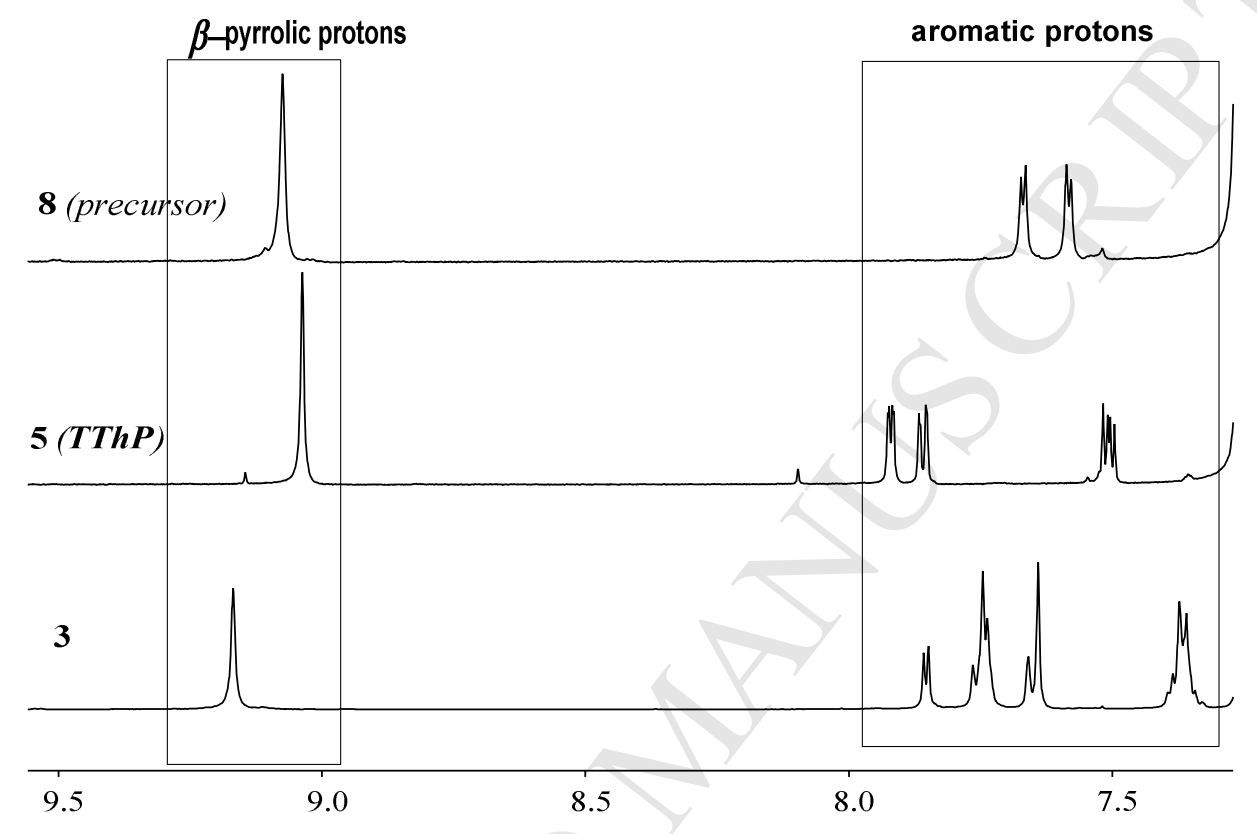

Figure 1. Comparative partial ${ }^{1} \mathrm{H}$ NMR spectra of the known TThP 5 and 8 , and of the new dendrimer 3 in the aromatic region.

\section{Photophysical Properties}

UV/Vis absorption and emission spectra were next recorded for the new tetra(thien-2yl)porphyrin dendrimers 3 and $\mathbf{4}$ in dichloromethane solutions (Table 1). Then, for comparison, the bare TThP as corresponding reference, and molecules with similar structures: the tetraphenylporphyrin analogues $\mathbf{1}$ and $\mathbf{2},{ }^{[7]}$ were chosen (Scheme 1). This comparison will permit the analysis of the influence of various aromatic groups at meso-positions on the optical properties of these derivatives.

\section{Absorption spectra}


The dendrimers $\mathbf{3}$ and $\mathbf{4}$ present two distinct components in their UV-visible absorption spectra shown in Figure 2 : (i) an intense Soret-band around $435 \mathrm{~nm}$ and four Q-bands in the 500-700 $\mathrm{nm}$ spectral region, these are typical of free base porphyrin absorptions; (ii) a dendron-based absorption between 250-380 nm, absent for the reference compound 5 possessing no dendrons. In line with the presence of a more extended $\pi$-manifold on these porphyrins, the Soret bands for $\mathbf{3}$ and $\mathbf{4}$ are slightly red shifted when compared to that of $\mathbf{5}$ (Figure 2), while this band for $\mathbf{4}$ is slightly blue-shifted relative to $3(427 \mathrm{~nm} v$ s. $425 \mathrm{~nm})$; probably because the corresponding dendron (7) possessing two fluorenyl units in positions 3 and 5 of the phenyl linker is less conjugated with the central porphyrin than dendron 6 with only one fluorenyl group directly appended to the position 5 of the peripheral thienyl linkers. In the Q band region, 5 shows four well defined absorption bands, at energies such that $\mathrm{Q}_{\mathrm{y}}(1,0)>\mathrm{Q}_{\mathrm{y}}(0,0)>\mathrm{Q}_{\mathrm{x}}(1,0)>\mathrm{Q}_{\mathrm{x}}(0,0)$.

For dendrimer 3, $\mathrm{Q}_{y}(1,0), \mathrm{Q}_{\mathrm{y}}(0,0)$ and $\mathrm{Q}_{\mathrm{x}}(0,0)$ are clearly separated, whilst $\mathrm{Q}_{\mathrm{y}}(0,0)$ overlaps with $\mathrm{Q}_{\mathrm{x}}(1,0)$ and appears as a small shoulder. In contrast for dendrimer 4 , the three $\mathrm{Q}_{\mathrm{y}}(1,0), \mathrm{Q}_{\mathrm{y}}(0,0)$ and $\mathrm{Q}_{\mathrm{x}}(1,0)$ bands seriously overlap, while, as before, $\mathrm{Q}_{\mathrm{x}}(0,0)$ appears in a clearly distinct spectral range around $660 \mathrm{~nm}$. Regarding the dendron-based absorptions in the UV region, in line with expectations based on the number of fluorenyl groups incorporating overall four (3) or eight (4) fluorenyl units, that for $\mathbf{4}$ is largely stronger than twice that for $\mathbf{3}$, and thereby becomes also more intense than the Soret band.

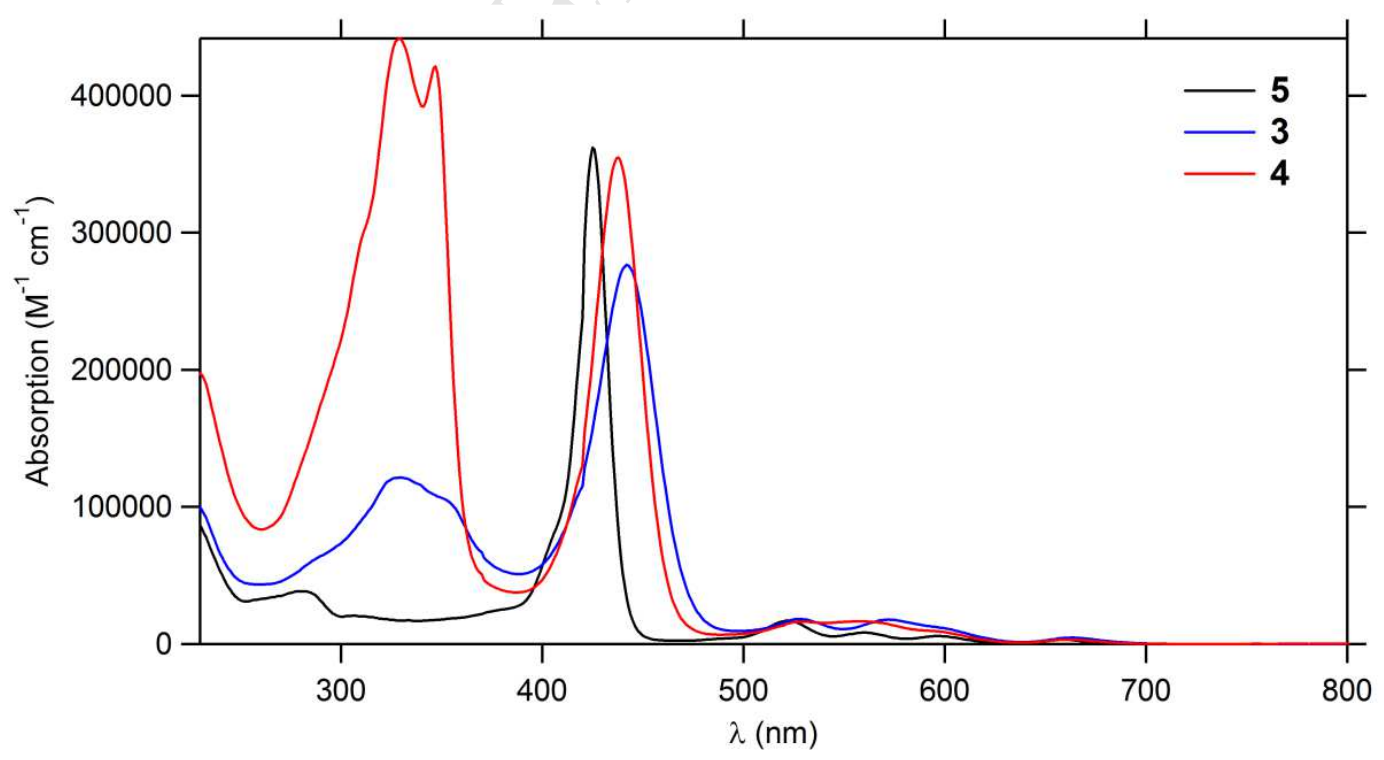

Figure 2. UV-visible absorption spectra of bare TThP (5), and of the TThP-cored dendrimers 3 and 4 in $\mathrm{CH}_{2} \mathrm{Cl}_{2}$. 


\section{Emission spectra}

Upon excitation in their Soret band (425 nm), the compounds $\mathbf{3}, \mathbf{4}$ and $\mathbf{5}$ emit in the red spectral range, between 650 and $820 \mathrm{~nm}$ (Fig. 3). Their normalized emission spectra were measured in dichloromethane (HPLC grade). As shown in Figure 3, after excitation, the reference compound 5 presents the two typical Q-emission bands: $\mathrm{Q}(0,0)$ and $\mathrm{Q}(0,1)$. In contrast, the dendrimer 3 and $\mathbf{4}$, present essentially only one broader emission band red-shifted relative to the $\mathrm{Q}(0,0)$ band of 5 . The shape of this band for 4, reveals however two strongly overlapped Q-bands possibly not resolved for $\mathbf{3}$. The spectral position of this band among $\mathbf{3}$ and $\mathbf{4}$ mirrors that of lowest energy $\mathrm{Q}$ bands, thus, that of $\mathbf{3}$ is also slightly red shifted compared to that of $\mathbf{4}$.

The fluorescence quantum yields found for 3, 4 and $5(4 \%, 2.5 \%$ and 5\%, respectively, see Table 1), albeit very similar, reveal a slight decrease when proceeding from reference 5 to compounds featuring higher generation dendrons at their periphery.

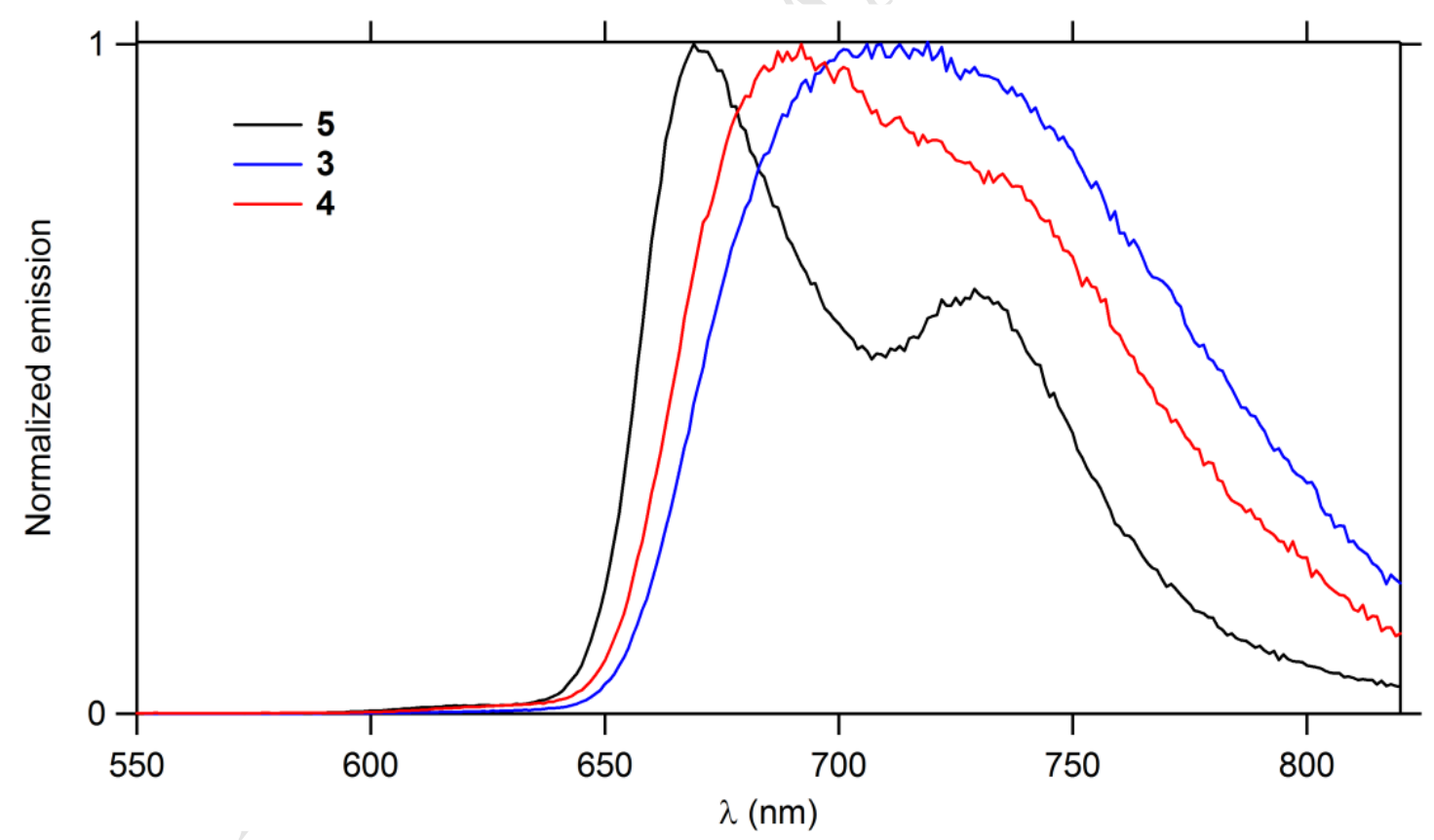

Figure 3. Emission spectra of $\mathbf{3}, \mathbf{4}$ and $\mathbf{5}$ excited in their Soret band in $\mathrm{CH}_{2} \mathrm{Cl}_{2}$ solution. 


\section{Energy transfer from fluorene units to the porphyrin core}

The existence of an energy transfer (ET) between the peripheral dendrons and the central tetra(thien-2-yl)porphyrin core was also probed. Thus, dendrimers $\mathbf{3}$ and $\mathbf{4}$ were excited at the wavelength corresponding to the dendron absorption (around $320 \mathrm{~nm}$ ) and the resulting emission spectra were measured for each compound (Fig. 4). The dendrimer 3 displays exclusively red emission, which reveals a very efficient ET from the peripheral dendrons to the porphyrin core. Dendrimer 4 also shows a strong red emission, but a broad and weak residual band around 375 $\mathrm{nm}$ is also observed. This suggests that the ET from the peripheral dendrons to the porphyrin core in $\mathbf{4}$ is less efficient than in $\mathbf{3}$, in line with previous findings for related dendrimers. ${ }^{[18]}$ This suggests that higher generation dendrons are less effective in transferring their energy to the porphyrin, in spite of their larger linear absorption.

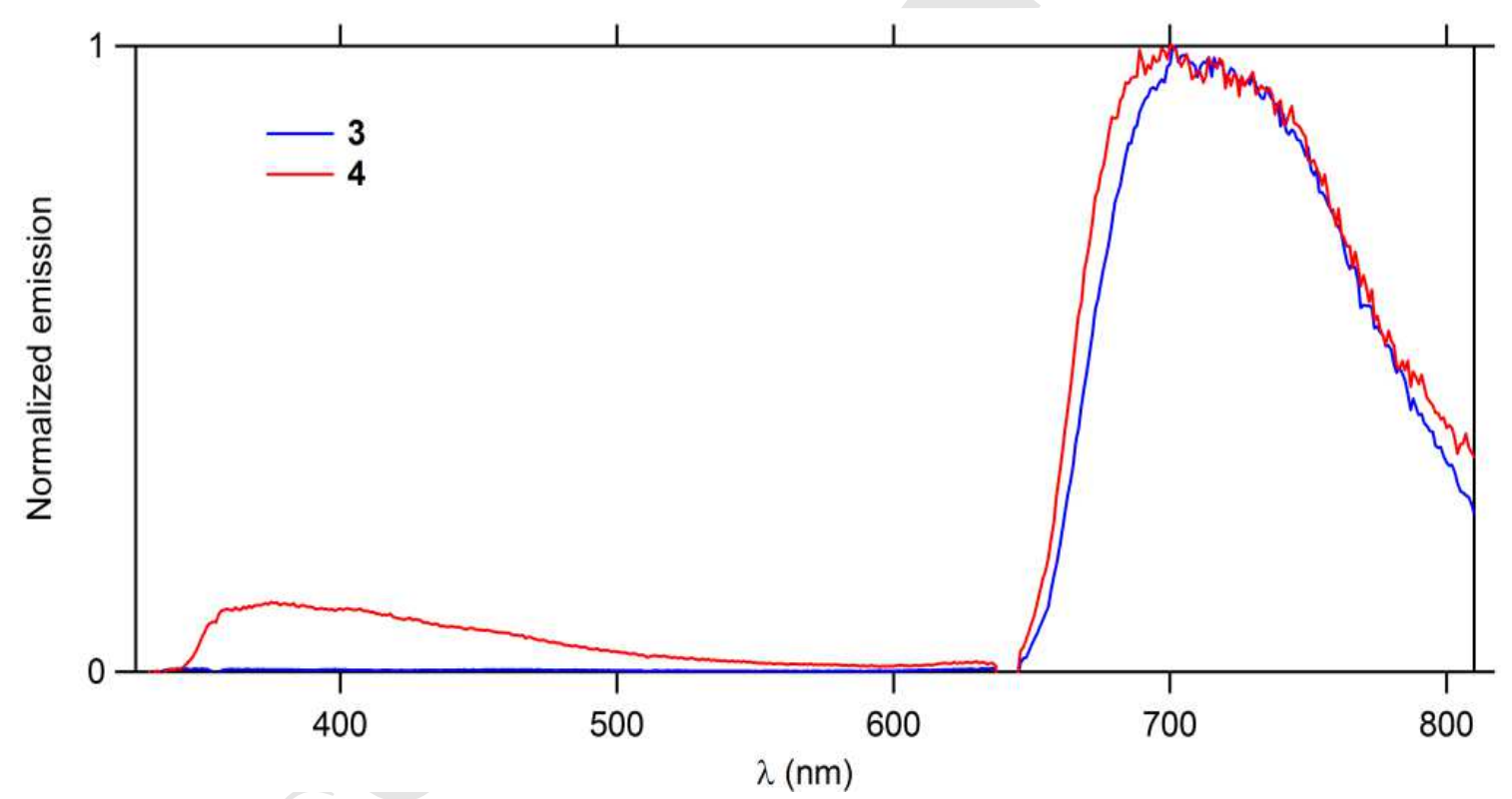

Figure 4. Emission spectra of 3 and $\mathbf{4}$ upon Excitation at Dendron Absorption $\left(\lambda_{\mathrm{Ex}}=320 \mathrm{~nm}\right)$ in $\mathrm{CH}_{2} \mathrm{Cl}_{2}$.

\section{Two-photon absorption}

Taking advantage of the fluorescence of these thienyl-cored dendrimers, their two-photon absorption (2PA) cross-sections were determined by two-photon excited fluorescence (TPEF) in dichloromethane, using the experimental protocol described by Xu and Webb. ${ }^{[20]}$ A fully 
quadratic dependence of the fluorescence intensity on the excitation power was observed for each sample at all the wavelengths of the spectra, indicating that the cross-sections determined are only due to 2PA. Compared to the $\sigma_{2}$ of $5(13 \mathrm{GM}$ at $790 \mathrm{~nm})$, a strong increase in the 2PA cross-sections is observed for both $\mathbf{3}$ and $\mathbf{4}$ (see Figure 5 and Table 1). Then, the "generation one; G1" dendrimer 4 exhibits a smaller 2PA than "generation zero; G0" dendrimer 3. Thus, it appears from this data that the combination of the meso-tetra(thien-2-yl)porphyrin core with simple fluorenyl alkynyl groups, like in dendron 6, is much more efficient for promoting 2PA than that with more extended dendrons such as 7. This is likely attributable to the lower conjugation between the peripheral fluorenyl groups and the central porphyrin core operative through the 1,3,5-trisubstituted benzene connectors in the latter case, recalling observations previously made with the $\mathbf{T P P}$-based analogues $\mathbf{1}$ and $\mathbf{2}^{[7]}$

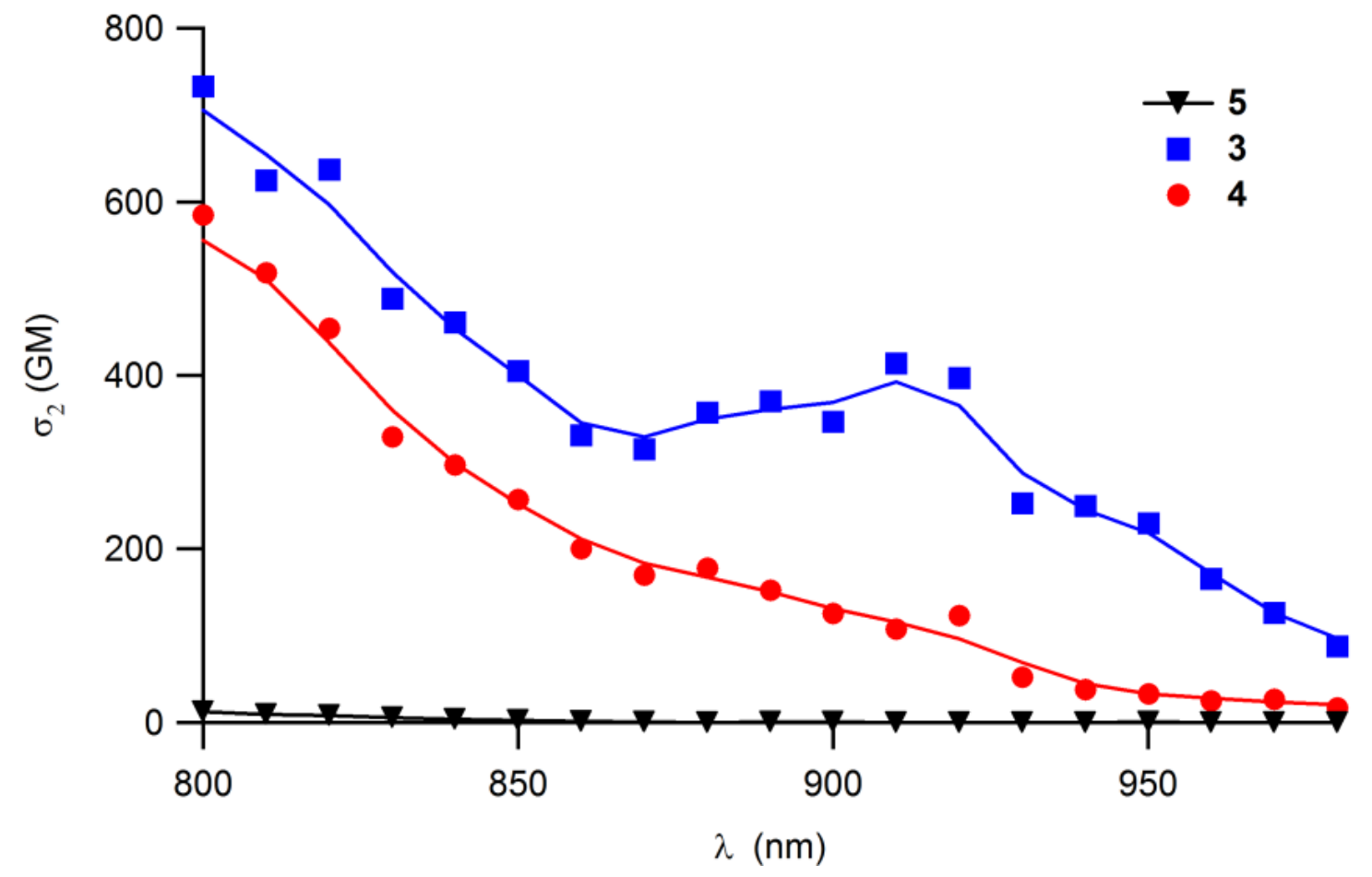

Figure 5. Two-photon absorption spectra for the reference compound $\mathbf{5}$ and for the new dendrimers $\mathbf{3}$ and 4 in $\mathrm{CH}_{2} \mathrm{Cl}_{2}$. 


\section{Oxygen sensitization}

In the continuation of the comparative study between the new TThP-based dendrimers and the previously studied TPP-based dendrimers, we also wondered about the oxygen-sensitizing capabilities of $\mathbf{3}$ and $\mathbf{4}$. So, the quantum yields of singlet oxygen generation were next determined for these TThP-based dendrimers (Table 1) and relevant figures of merit for 2PAimaging and sensitization were determined (Table 2).

Table 1. Photophysical properties in $\mathrm{CH}_{2} \mathrm{Cl}_{2}$ of the new meso-tetra(thien-2-yl)porphyrin dendrimers $\mathbf{3}$ and 4: comparison with the reference compound $\mathbf{5}$ and with their tetraphenylporphyrin analogues $\mathbf{1}$ and $\mathbf{2}$.

\begin{tabular}{|cccccccc|}
\hline Cpnd & $\begin{array}{c}\lambda_{\text {abs }} \\
(\text { dendron }) \\
(\mathrm{nm})\end{array}$ & $\begin{array}{c}\lambda_{\text {abs }} \\
(\text { Soret }) \\
(\mathrm{nm})\end{array}$ & $\begin{array}{c}\varepsilon_{\mathrm{max}}(\text { Soret }) \\
\left(\mathrm{M}^{-1} \mathrm{~cm}^{-1}\right)\end{array}$ & $\begin{array}{c}\lambda_{\mathrm{em}} \\
(\mathrm{nm})\end{array}$ & $\Phi_{\mathrm{F}}{ }^{a}$ & $\Phi_{\Delta}{ }^{b}$ & $\begin{array}{c}\sigma_{2}{ }^{c} \\
(\mathrm{GM})\end{array}$ \\
\hline $\mathbf{5}$ & - & 425 & 362000 & 670,729 & $0.05^{e}$ & $0.78^{f}$ & 13 \\
\hline $\mathbf{3}$ & $\mathbf{3 3 0}$ & $\mathbf{4 4 2}$ & $\mathbf{2 7 6} \mathbf{4 0 0}$ & $\mathbf{7 1 0}$ & $\mathbf{0 . 0 4}$ & $\mathbf{0 . 7 3}$ & $\mathbf{7 3 0}$ \\
$\mathbf{1}^{\boldsymbol{d}}$ & 324 & 427 & - & 657,724 & 0.20 & 0.70 & 380 \\
\hline $\mathbf{4}$ & 329 & 438 & 354000 & 690 & 0.025 & 0.50 & 580 \\
$\mathbf{2}^{\boldsymbol{d}}$ & 330 & 425 & - & 655,721 & 0.19 & 0.65 & 190 \\
\hline
\end{tabular}

${ }^{a}$ Fluorescence quantum yield determined relative to TPP in toluene $\left(\Phi_{\mathrm{F}}=0.11\right)$.

${ }^{b}$ Singlet oxygen formation quantum yield determined relative to tetraphenylporphyrin in dichloromethane $\left(\Phi_{\Delta}[\mathrm{TPP}]=0.60\right)$.

${ }^{c}$ Intrinsic 2PA cross-sections at $800 \mathrm{~nm}$ measured by TPEF in the femtosecond regime; a fully quadratic dependence of the fluorescence intensity on the excitation power was observed for each sample at all the wavelengths of the spectra.

${ }^{d}$ from ref. [7b]

${ }^{e}$ Quantum yield values $\left(\Phi_{\mathrm{F}}\right.$ between 0.0046 and $0.012^{[10 \mathrm{~b}, 21]}$ have been previously reported for that compound in toluene, and of $0.01^{[12]}$ in $\mathrm{CHCl}_{3}$.

${ }^{f}$ Quantum yield values $\left(\Phi_{\Delta}\right)$ of 0.46 have been previously reported for that compound in toluene and of 0.50 for TPP in $\mathrm{CHCl}_{3}$. ${ }^{[12]}$ 
Table 2. Two-photon brightness and two-photon singlet oxygen production of thienyl-cored porphyrin dendrimers $3, \mathbf{4}$, and comparison with their phenyl-cored porphyrin analogues $\mathbf{1}$ and $\mathbf{2}$.

\begin{tabular}{|ccc|}
\hline Compound & $\sigma_{2} . \Phi_{\mathrm{F}}(\mathrm{GM})^{a}$ & $\sigma_{2} . \Phi_{\Delta}(\mathrm{GM})^{b}$ \\
\hline $\mathbf{3}$ & $\mathbf{2 9}$ & $\mathbf{5 3 3}$ \\
$\mathbf{1}^{\mathrm{c}}$ & 76 & 266 \\
$\mathbf{4}$ & 17 & 290 \\
$\mathbf{2}^{\mathrm{c}}$ & 36 & 123 \\
\hline
\end{tabular}

${ }^{a}$ Two-photon brightness.

${ }^{b}$ Figure of merit of the two-photon excited singlet oxygen production.

${ }^{c}$ From Ref [7b].

\section{DISCUSSION}

We have synthesized and characterized a new series of thienyl-cored porphyrin dendrimers $\mathbf{3}$ and 4. When the linear optical properties of these new derivatives are compared to those of their phenyl analogues $\mathbf{1}$ and $\mathbf{2},{ }^{[7]}$ the Soret band of the tetra(thien-2-yl) porphyrins are red shifted compared to that of their TPP-cored analogues, a feature initially attributed to the inductive effect of the thienyl groups, ${ }^{[21]}$ but now recognized as being indicative of a better $\pi$-conjugation of the peripheral dendrons with the central porphyrin core. ${ }^{[14,21-22]}$ The next obvious statement is a five-to-six fold decrease in their fluorescence quantum yields, which can be related to the presence of sulfur atoms at their periphery, the latter possibly favoring a non-radiative decay process via spin-orbit coupling. ${ }^{[12,21]}$ As expected, lifetime measurements (Supporting Information) indicate a much faster non radiative decay rate for the thienyl-cored porphyrins compared to their phenyl analogues, in line with a possible heavy atom effect. However, based on this data, the slight decrease in fluorescence quantum yield stated along the thienyl series (following the order: $\mathbf{5}>\mathbf{4}>\mathbf{3}$ ) is more attributable to a decrease of the intrinsic fluorescence rate and not to an increase in the rate of the non-radiative process (intersystem crossing and internal conversion). Thus, due to their much lower fluorescence quantum yields, $\mathbf{3}$ and $\mathbf{4}$ exhibit 
also a significantly lower two-photon brightness $\left(\sigma_{2} . \Phi_{\mathrm{F}}\right)$ than their TPP analogues $\mathbf{1}$ and $\mathbf{2}$ (Table 2).

Considering the significant 2PA cross-sections previously determined for phenylporphyrins $\mathbf{1}$ and 2 (Scheme 1), ${ }^{[7]}$ we have also turned our attention to the $2 \mathrm{PA}$ properties of the thienyl analogues 3 and $\mathbf{4}$ and determined their $\sigma_{2}$ values. Comparison with the former two-photon absorbers (1 and 2) reveals a clear improvement of the 2PA properties of the new thienyl derivatives 3 and 4, respectively. Replacement of the 1,4-phenylene spacer at the periphery of the porphyrin core by a 2,5-thienylene one allows the significant improvement of the 2PA crosssections $\left(\sigma_{2}\right)$ of the resulting chromophores. Thus, a twofold enhancement when progressing from 1 to 3 and threefold enhancement when progressing from 2 to 4 , is stated (Table 1). In line with the well-known fact that the 2,5-thienylene spacer allows a better conjugation than the 1,4phenylene one ${ }^{[21,22]}$ this study suggests that improving the conjugation between the porphyrin core and its meso substituents is the key factor for improving their 2PA capabilities. Compared to previous approaches that we used to ameliorate the 2PA cross-sections of porphyrin, such as for instance appending electron-rich metal alkynyl substituents in the para position at the mesophenyl groups, ${ }^{[23]}$ the present approach gives more modest improvements in $\sigma_{2}$ but allows the maintenance of a sufficient fluorescence for measuring the 2PA cross-section by TPEF.

The importance of thienyl groups for favoring third-order NLO response over phenyl ones is often attributed to the strong polarizability of the sulfur atom. ${ }^{[24-26]}$ In this respect, carbon disulfide or other sulfur-rich compounds are often used as standards in $3^{\text {rd }}$ order NLO. ${ }^{[25,27]}$ While the increased polarizability of sulfur certainly contributes to enhance the nonlinear refractive properties of a given molecule, we think that its contribution to nonlinear absorption processes such as $2 \mathrm{PA}$ is possibly less important here. Rather, and in line with what precedes, we believe that it is the increased conjugation through the 2,5-thienylene linker in $\mathbf{3}$ and $\mathbf{4}$ (relative to that previously operative through the 1,4-phenylene in $\mathbf{1}$ and 2) that presently constitutes the determining factor. First, compared to meso-tetraphenylporphyrin (TPP), a reduced steric hindrance was established for the smaller 5, because the thien-2-yl substituent lacks one ortho- 
phenyl proton minimizing thereby the steric interaction with the $\beta$-pyrrolic protons. ${ }^{[22,28]}$ As a consequence, thiophene rings can adopt more coplanar conformations than benzene rings and are more strongly conjugated with the porphyrin core in solution for $\mathbf{5}$ than for mesotetraphenylporphyrin (TPP), inducing the observed bathochromic shift in the absorption spectra of the meso-tetra(thien-2-yl)porphyrins relative to their tetraphenyl analogues (Figure 2). ${ }^{[29]}$ Even if in the solid state, comparable dihedral angles $\left(\approx 60^{\circ}\right)^{[30]}$ between the peripheral rings and the central porphyrin core, have often been observed, ${ }^{[31]}$ more possibilities to reach conjugated conformations in solution are offered by the 2,5-thiophene groups. ${ }^{[22,28]}$ Then, besides this purely conformational effect, the lower aromaticity of the thiophene ring relative to that of benzene certainly also contributes to enforce cross-conjugation between its 2 and 5 positions compared to the 1,4-phenylene spacer, as revealed by studies on conducting polyaromatic polymers. ${ }^{[32]}$

Finally, in the continuation of our comparative study with $\mathbf{1}$ and $\mathbf{2}$, we also wondered about the oxygen-sensitizing capabilities of new dendrimers 3 and $\mathbf{4}$. When compared to those of their TPP-cored analogues (Table 2), the TThP derivatives $\mathbf{3}$ and $\mathbf{5}$ exhibit comparably higher values than those previously determined for $\mathbf{1}$ and for meso-tetraphenylporphyrin $\left(\mathbf{T P P} ; \Phi_{\Delta}=0.60\right),{ }^{[7]}$ (An opposite trend had been previously reported for these two compounds in toluene; see footnote $\mathrm{f}$ in Table 1), the highest quantum yield of singlet oxygen generation remaining to the bare porphyrin 5. In contrast, TThP-cored dendrimer 4 seems slightly less effective for photosensitizing oxygen than the corresponding phenyl one (2). At least for the two former compounds, this result can also be related to a faster intersystem crossing favored by the heavy sulfur atoms which enhances population of the first triplet states and therefore stimulate oxygen sensitization. However, the comparably lower efficiency in oxygen sensitization found for the dendrimer $\mathbf{4}$ relative to $\mathbf{2}$ suggests that other factors (than just this heavy atom effect) come also in play in the sensitization process. Nevertheless, even for $\mathbf{4}$, the quantum yield of singlet oxygen formation $\left(\Phi_{\Delta}\right)$ remains close to that of $\mathbf{2}$ (Table 1). As a result, thanks to their maintained singlet oxygen generation quantum yields and quite improved $\sigma_{2}$ values, 3 and $\mathbf{4}$ exhibit figures of merit for two-photon singlet oxygen production $\left(\sigma_{2} . \Phi_{\Delta}\right)$ at least twice as large as those of their analogues $\mathbf{1}$ and $\mathbf{2}$ (Table 2). Thus, while certainly less attractive than $\mathbf{1}$ and $\mathbf{2}$ for 2PA-based 
theranostic developments, ${ }^{[33]}$ due to their diminished fluorescence, meso-tetra(thien-2yl)porphyrins remain nevertheless very interesting chromophores for developing new photosensitizers for two-photon excited photodynamic therapy (2PA-PDT) in the future after suitable functionalization to bio-compatibilize these molecules.

\section{Conclusions}

We have synthesized and characterized two new meso-tetra(thien-2-yl)porphyrin-based dendrimers 3 and 4, and the known parent meso-tetra(thien-2-yl)porphyrin (5) as a reference. These new compounds were obtained via a convergent approach from the corresponding aldehyde-terminated dendrons, 6 and 7 respectively, and pyrrole under Lindsey conditions, the dendritic precursors being themselves synthesized through iterative Sonogashira and CoreyFuchs procedures. We show that these chromophores feature conjugated arms terminated by 2fluorenyl groups which act as light harvesting antenna, absorbing light in the UV region before transferring it to the porphyrin core which partially re-emits it by fluorescence, as red light. For this process, we show that they exhibit rather low fluorescence quantum yields (5-3\%), similar to the reference compound $\mathbf{5}$, but smaller than the corresponding TPP-cored dendrimers ( $\mathbf{1}$ and $\mathbf{2}$ and that the energy transfer (ET) process from peripheral dendrons to central porphyrin core is quite efficient, particularly for the smaller (but fully conjugated) dendrimer $\mathbf{3}$.

The two-photon absorption (2PA) cross-sections $\left(\sigma_{2}\right)$ of $\mathbf{3}$ and $\mathbf{4}$ were also measured by TPEF, revealing that their $\sigma_{2}$ values were strongly enhanced compared to that of $\mathbf{5}$, but also compared to those of their TPP analogues $\mathbf{1}$ and 2, suggesting that conjugation between the peripheral fluorenyl units and the central porphyrin core is determining for improving the $2 \mathrm{PA}$ performances. Finally, we have shown that both $\mathbf{3}$ and $\mathbf{4}$ can still photo-sensitize oxygen with a better or comparable efficiency than $\mathbf{1}$ and $\mathbf{2}$ when excited in their Soret band, giving rise to far better figures of merit than their TPP analogues for two-photon excited photodynamic therapy (2PA-PDT). Given the rather facile access to this new class of dendrimeric porphyrins and considering the relatively large versatility of the synthesis, this work opens very attractive perspectives for designing new photosensitizers for 2PA-based PDT. 


\section{EXPERIMENTAL SECTION}

\section{General}

Unless otherwise stated, all solvents used in reactions were distilled using common purification protocols, ${ }^{[34]}$ except DMF and ${ }^{\mathrm{i}} \operatorname{Pr}_{2} \mathrm{NH}$ which were dried on molecular sieves (3 $\mathrm{A}$ ). Compounds were purified by chromatography on silica gel using different mixtures of eluents as specified. ${ }^{1} \mathrm{H}$ and ${ }^{13} \mathrm{C}$ NMR spectra were recorded on BRUKER Ascend 400 and 500 at $298 \mathrm{~K}$. The chemical shifts are referenced to internal tetramethylsilane. High-resolution mass spectra were recorded on different spectrometers: a Bruker MicrOTOF-Q II, a Thermo Fisher Scientific QExactive in ESI positive mode and a Bruker Ultraflex III MALDI Spectrometer at CRMPO (Centre Regional de Mesures Physiques de l'Ouest) in Rennes. Reagents were purchased from commercial suppliers and used as received.

\section{Synthesis of Porphyrin Dendrimers}

The dendrons 6 and 7 were synthesized as described earlier by our group, ${ }^{[7,18-19]}$ and the intermediate 5-iodo-tetrathienylporphyrin $(\mathbf{8})$ as reported. ${ }^{[30]}$

Meso-(2-((9, 9-dibutyl-fluoren-2-yl)ethynyl)-thienyl)porphyrin (3): In a Schlenk tube, 5-iodotetrathienylporphyrin (5) (117 mg, $0.1 \mathrm{mmol}, 1$ equiv.), the dendron 6 (139 mg, $0.5 \mathrm{mmol}, 5$ equiv.), $\mathrm{Pd}\left(\mathrm{PPh}_{3}\right)_{2} \mathrm{Cl}_{2}$ (1.9 mg, $0.45 \mathrm{mmol}, 0.6 \%$ equiv.) and $\mathrm{CuI}(1 \mathrm{mg}, 0.5 \mathrm{mmol}, 0.3 \%$ equiv.) were stirred in a mixture of DMF $(4 \mathrm{~mL})$ and ${ }^{i} \mathrm{Pr}_{2} \mathrm{NH}(4 \mathrm{~mL})$ under argon, following the previously described protocole. ${ }^{[36 b]}$ The system was degassed by freeze-pump-thaw twice and heated for $48 \mathrm{~h}$ at $95{ }^{\circ} \mathrm{C}$. After evaporation of volatiles, the residue was purified by silica chromatography (heptane $/ \mathrm{CH}_{2} \mathrm{Cl}_{2}=5: 1$ ), and recrystallized from THF providing the title compound as a dark violet powder (72 mg, $37 \%$ yield). ${ }^{1} \mathrm{H}$ NMR $\left(400 \mathrm{MHz}, \mathrm{CDCl}_{3}, \mathrm{ppm}\right): \delta=$ $9.17\left(\mathrm{~s}, 8 \mathrm{H}, \mathrm{H}_{\beta-\mathrm{Pyr}}\right), 7.85\left(\mathrm{~d}, 4 \mathrm{H}, J=3.6 \mathrm{~Hz}, \mathrm{H}_{\mathrm{Th}}\right), 7.76-7.74\left(\mathrm{~m}, 12 \mathrm{H}, \mathrm{H}_{\mathrm{Flu}}\right), 7.65\left(\mathrm{~m}, 8 \mathrm{H}, \mathrm{H}_{\mathrm{Th}}+\right.$ $\left.\mathrm{H}_{\mathrm{Flu}}\right), 7.40-7.33\left(\mathrm{~m}, 12 \mathrm{H}, \mathrm{H}_{\mathrm{Flu}}\right), 2.09-1.98\left(\mathrm{~m}, 16 \mathrm{H}, \mathrm{H}_{\mathrm{Bu}}\right), 1.17-1.08\left(\mathrm{~m}, 16 \mathrm{H}, \mathrm{H}_{\mathrm{Bu}}\right), 0.72(\mathrm{t}, 24 \mathrm{H}$, $\left.J=7.2 \mathrm{~Hz}, \mathrm{H}_{\mathrm{Bu}}\right), 0.68-0.54\left(\mathrm{~m}, 16 \mathrm{H}, \mathrm{H}_{\mathrm{Bu}}\right),-2.58 \mathrm{ppm}(\mathrm{s}, 2 \mathrm{H}, \mathrm{NH}) ;{ }^{13} \mathrm{C} \mathrm{NMR}\left(100 \mathrm{MHz}, \mathrm{CDCl}_{3}\right.$, ppm): $\delta=151.1,150.9,144.0,141.9,140.4,134.1,131.1,130.6,127.6,126.9,126.5,126.0$, 
122.9, 121.0, 120.1, 119.8, 111.9, 110.0, 95.7, 82.5, 55.2, 40.2, 31.3, 29.7, 26.0, 23.1, 13.8 ppm. UV-vis $\left[\mathrm{CH}_{2} \mathrm{Cl}_{2}, \mathrm{~nm}\right]: \lambda_{\max }=442,529,570,595,662$. HRMS-ESI for $\mathrm{C}_{128} \mathrm{H}_{118} \mathrm{~N}_{4} \mathrm{~S}_{4}: \mathrm{m} / \mathrm{z}=$ $1839.8266[\mathrm{M}+\mathrm{H}]^{+}$(calcd: 1839.8312); $\mathrm{m} / \mathrm{z}=920.4184[\mathrm{M}+2 \mathrm{H}]^{2+}$ (calcd: 920.4192). Anal. Calcd (\%) for $\mathrm{C}_{128} \mathrm{H}_{118} \mathrm{~N}_{4} \mathrm{~S}_{4}$ 2THF: C 82.30; H 6.81; N 2.82 Found: C 82.46; H 7.00; N 2.34.

Meso-(2-((3,5-bis((9,9-dibutyl-fluoren-2-yl)ethynyl)phenyl)ethynyl)thienyl)porphyrin (4): In a Schlenk tube, of 5-iodo-tetrathienylporphyrin (5) (36 mg, 0.03 mmol, 1 equiv.), dendron 7 (100 mg, $0.1 \mathrm{mmol}, 4.5$ equiv. $), \mathrm{Pd}\left(\mathrm{PPh}_{3}\right)_{2} \mathrm{Cl}_{2}(1 \mathrm{mg}, 0.1 \mathrm{mmol}, 0.6 \%$ equiv. $)$ and $\mathrm{CuI}(0.1 \mathrm{mg}, 0.1$ mmol, $0.3 \%$ equiv.) were added in a mixture of DMF $(3 \mathrm{~mL})$ and ${ }^{i} \operatorname{Pr}_{2} \mathrm{NH}(3 \mathrm{~mL})$ under argon (see above). The system was degassed by freeze-pump-thaw twice and heated for $48 \mathrm{~h}$ at $95{ }^{\circ} \mathrm{C}$. After evaporation of volatiles, the dark residue was purified by silica chromatography (heptane $/ \mathrm{THF}=8: 1)$, providing the title compound as a dark violet powder $(41 \mathrm{mg}, 40 \%$ yield $) .{ }^{1} \mathrm{H} \mathrm{NMR}$ $\left(400 \mathrm{MHz}, \mathrm{CDCl}_{3}, \mathrm{ppm}\right): \delta=9.18\left(\mathrm{~s}, 8 \mathrm{H}, \mathrm{H}_{\beta-\mathrm{Pyr}}\right), 7.87\left(\mathrm{~d}, 4 \mathrm{H}, J=3.2 \mathrm{~Hz}, \mathrm{H}_{\mathrm{Th}}\right), 7.82(\mathrm{~m}, 8 \mathrm{H}$, $\left.\mathrm{H}_{\mathrm{Flu}}+\mathrm{H}_{\mathrm{Ph}}\right), 7.76\left(\mathrm{~d}, 4 \mathrm{H}, J=3.2 \mathrm{~Hz}, \mathrm{H}_{\mathrm{Th}}\right), 7.71\left(\mathrm{~d}, 20 \mathrm{H}, J=7.2 \mathrm{~Hz}, \mathrm{H}_{\mathrm{Flu}}+\mathrm{H}_{\mathrm{Ph}}\right), 7.56-7.53(\mathrm{~m}$, $\left.14 \mathrm{H}, \mathrm{H}_{\mathrm{Flu}}\right), 7.35-7.34\left(\mathrm{~m}, 26 \mathrm{H}, \mathrm{H}_{\mathrm{Flu}}\right), 2.00\left(\mathrm{~m}, 32 \mathrm{H}, \mathrm{H}_{\mathrm{Bu}}\right), 1.14-1.06\left(\mathrm{~m}, 32 \mathrm{H}, \mathrm{H}_{\mathrm{Bu}}\right), 0.69(\mathrm{t}, 48 \mathrm{H}$, $\left.J=7.2 \mathrm{~Hz}, \mathrm{H}_{\mathrm{Bu}}\right), 0.65-0.54\left(\mathrm{~m}, 32 \mathrm{H}, \mathrm{H}_{\mathrm{Bu}}\right),-2.59(\mathrm{~s}, 2 \mathrm{H}, \mathrm{NH}) ;{ }^{13} \mathrm{C} \mathrm{NMR}\left(100 \mathrm{MHz}, \mathrm{CDCl}_{3}\right.$, ppm): $\delta=151.1,150.9,144.6,141.9,140.4,134.2,133.7,131.8,130.7,127.7,126.9,126.2$, $125.8,124.5,123.7,123.0,120.9,120.1,119.7,111.8,93.1,92.0,87.9,83.3,55.1,40.2,31.4$, 29.8, 26.0, 23.1, 13.9 ppm. UV-vis $\left[\mathrm{CH}_{2} \mathrm{Cl}_{2}, \mathrm{~nm}\right]: \lambda_{\max }\left(\varepsilon_{\max }\right.$ in $\left.10^{3} \mathrm{M}^{-1} \mathrm{~cm}^{-1}\right)=438,530,560,594$, 660, MS (Maldi-TOF) for $\mathrm{C}_{252} \mathrm{H}_{230} \mathrm{~N}_{4} \mathrm{~S}_{4}: \mathrm{m} / \mathrm{z}=3439.658[\mathrm{M}+\mathrm{H}]^{+}$(calcd: 3439.69979). Anal. Calcd (\%) for $\mathrm{C}_{252} \mathrm{H}_{230} \mathrm{~N}_{4} \mathrm{~S}_{4}$ : C 87.91; H 6.73; N 1.63. Found: C 87.70; H 6.89; N 1.21.

\section{Some}

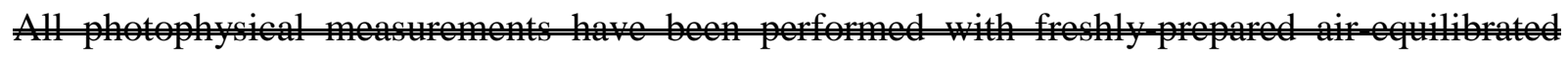
solutions at roem temperature $(298 \mathrm{~K})$. UV Vis abserption spectra were recorded on a Jaseo V

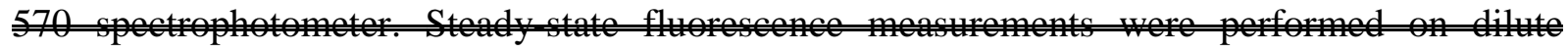




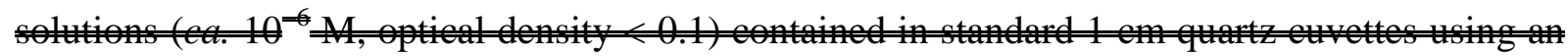
Edimburgh Instrument (FLS920) spectrometer in photon-counting mode. Fully corrected

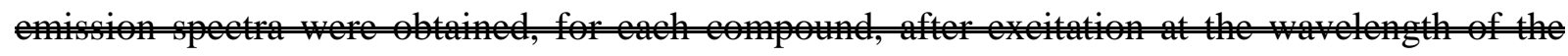

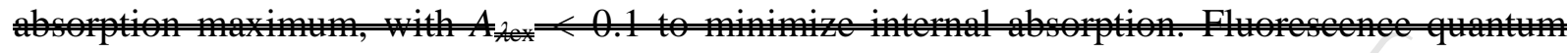
-

\section{Two-Photon-Abserption Experiments}

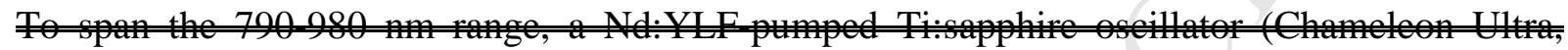

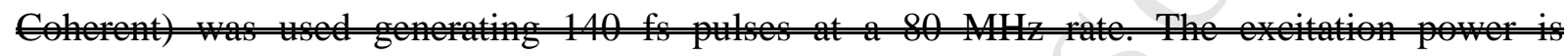
controlled using neutral density filters of varying optical density mounted in a computer-

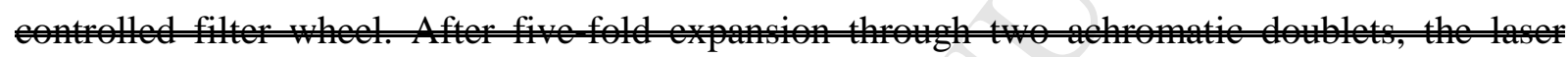

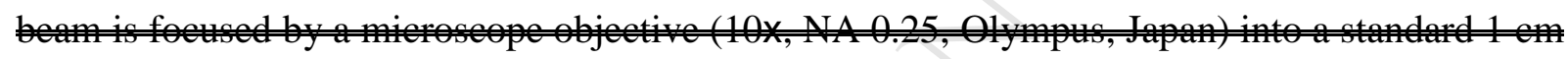

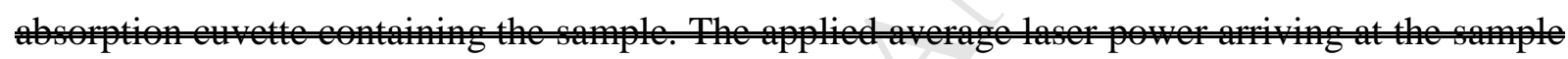

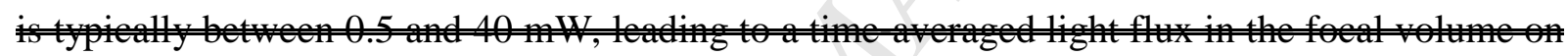
the order of $0.1-10 \mathrm{~mW} / \mathrm{mm}^{2}$. The flurescence from the sample is collect in epifluoresence

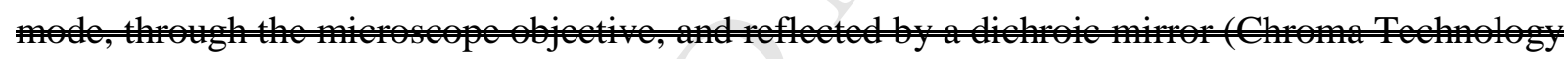

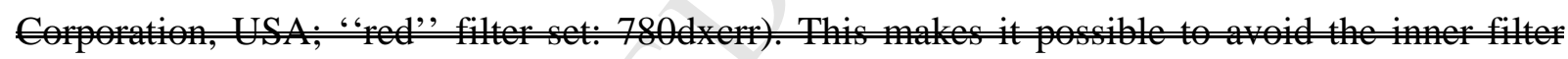

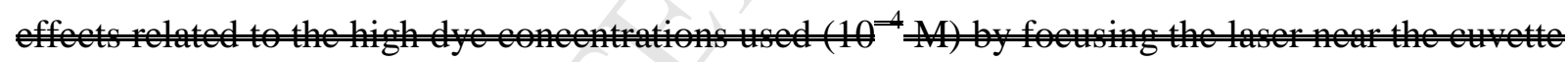

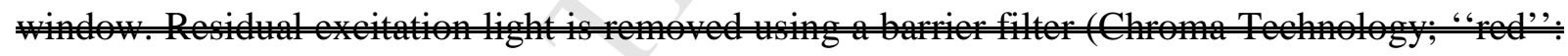
e750sp-2p). The fluorescence is coupled into a 600 pm multimode fiber by an achromatic

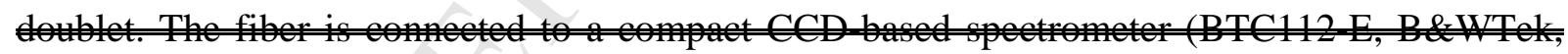

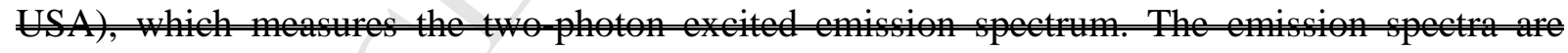

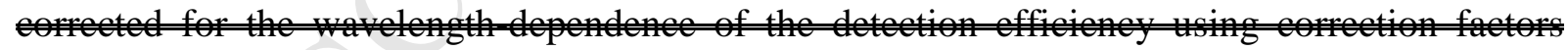

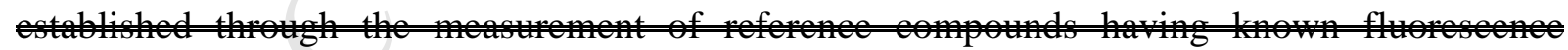
emision specta. Briefly, the allows for on

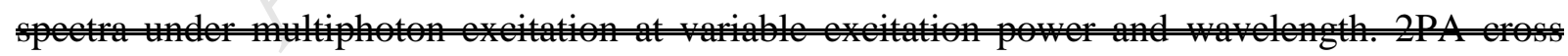
stions ( $\sigma_{2}$ ) were determined from the flo (TPEF) $\left(\Theta_{2}=\Phi_{F}\right)$ and the flum $10^{-4} \mathrm{M}$

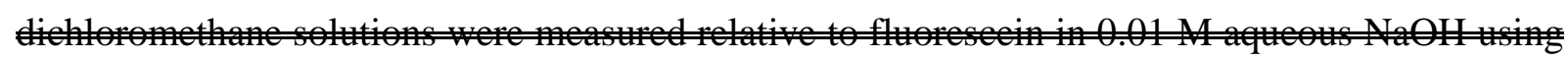
the ll- 


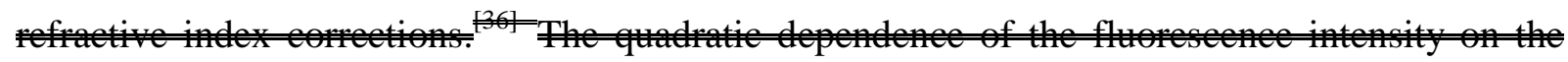
excitation power was checked for each sample and all wavelengths.

\section{Measurement of Singlet 0 xygen-Quantum-Yields $\left(\Phi_{\Delta}\right.$ F}

Meawrements tamp. The miscol $1272 \mathrm{~mm}$ was de

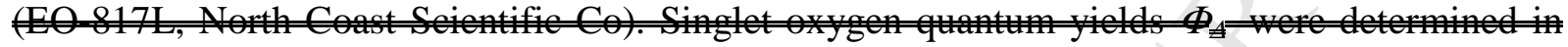

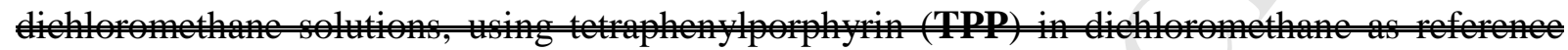

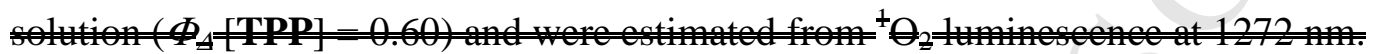

- ASSOCIATED CONTENT

Supporting Informations. ${ }^{1} \mathrm{H}$ NMR and ${ }^{13} \mathrm{C}$ NMR of all new compounds. Two-photon absorption spectra of $\mathbf{3}, \mathbf{4}$ and $\mathbf{5}$ and comparison with their one-photon absorption spectra.

\section{- AUTHOR INFORMATION}

\section{Corresponding Author}

*Email: christine.paul@univ-rennes1.fr or christine.paul@insa-rennes.fr

\section{ACKNOWLEDGEMENTS}

The authors acknowledge CNRS for their financial support and China Scholarship Council (CSC) for PhD funding (XZ and LS) as well as "the Ministère de l'Enseignement Supérieur et de la Recherche Scientifique de Tunisie" for PhD funding (SA). This project was supported by the departmental committees CD35 and CD85 of the "Ligue contre le Cancer du Grand-Ouest". We also thank Guillaume Clermont (ISM) for his help in the two-photon and singlet oxygen measurements. 


\section{REFERENCES AND NOTES}

[1] a) G. S. He, L.-S. Tan, Q. Zheng, P. N. Prasad, Chem. Rev. 2008, 108, 1245; b) M. Pawlicki, H. A. Collins, R. G. Denning, H. L. Anderson, Angew. Chem. Int. Ed. 2009, 48, 3244; c) S. R. Marder, Chem. Commun., 2006, 131.

[2] J. L. Brédas, C. Adant, P. Tackx, A. Persoons, Chem. Rev. 1994, 94, 243.

[3] L. B. Josefsen, R. W. Boyle, Theranostics 2012, 2, 916.

[4] a) M. Khurana, H. A. Collins, A. Karotki, H. L. Anderson, D. T. Cramb, B. C. Wilson, Photochem. Photobiol. 2007, 83,1441; b) J. R. Starkey, A. K. Rebane, M. A. Drobizhev, F. Meng, A. Gong, A. Elliott, K. McInnerney, C. W. Spangler, Clin. Cancer Res. 2008, 14, 6564; c) H. A. Collins, M. Khurana, E. H. Moriyama, A. Mariampillai, E. Dahlstedt, M. Balaz, M. K. Kuimova, M. Drobizhev, V. X. D. Yang, D. Phillips, A. Rebane, B. C. Wilson, H. L. Anderson, Nat. Photonics 2008, 2, 420; d) J. G. Croissant, S. Picard, D. Aggad, M. Klausen, C. Mauriello Jimenez, M. Maynadier, O. Mongin, G. Clermont, E. Genin, X. Cattoën, M. Wong Chi Man, L. Raehm, M. Garcia, M. Gary-Bobo, M. Blanchard-Desce, J.-O. Durand, J. Mater. Chem. B 2016, 4, 5567; e) W. Hu, T. He, R. Jiang, J. Yin, L. Li, X. Lu, H. Zhao, L. Zhang, L. Huang, H. Sun, W. Huang and Q. Fan, Chem. Commun. 2017, 53, 1680; f) F. Bolze; S. Jenni, A. Sour, V. Heitz, Chem. Commun. 2017, 53, 12857; g) M. Lan, S. Zhao, Y. Xie, J. Zhao, L. Guo, G. Niu, Y. Li, H. Sun, H. Zhang, W. Liu, J. Zhang, P. Wang, W. Zhang, ACS Appl. Mater. Interfaces 2017, 9, 14590; h) F. Hammerer, F. Poyer, L. Fourmois, S. Chen, G. Garcia, M.-P. Teulade-Fichou, P. Maillard, F. Mahuteau-Betzer, Bioorg. Med. Chem. 2018, 26, 107.

[5] a) F. Terenziani, C. Katan, E. Badaeva, S. Tretiak, M. Blanchard-Desce, Adv. Mater. 2008, 20, 4541; b) H. M. Kim, B. R. Cho, Chem. Commun. 2009, 153.

[6] a) P. Prabhu, V. Patravale, J. Biomed. Nanotechnol. 2012, 8, 859; b) J. Bhaumik, A. K. Mittal, A. Banerjee, Y. Chisti, U. C. Banerjee, Nano Res. 2015, 8, 1373; c) J. Schmitt, V. Heitz, A. Sour, F. Bolze, P. Kessler, L. Flamigni, B. Ventura, C. S. Bonnet, E. Toth, Chem. Eur. J. 2016, 22, 2775.

[7] a) D. Yao, V. Hugues, M. Blanchard-Desce, O. Mongin, C. O. Paul-Roth, F. Paul, New J. Chem. 2015, 39, 7730; b) D. Yao, X. Zhang, O. Mongin, F. Paul, C. O. Paul-Roth, Chem. Eur. J. 2016, 22, 5583. 
[8] a) M. Albota, D. Beljonne, J. L. Brédas, J. E. Ehrlich, J. Y. Fu, A. A. Heikal, S. E. Hess, T. Kogej, M. D. Levin, S. R. Marder, D. McCord-Maughon, J. W. Perry, H. Röckel, M. Rumi, G. Subramaniam, W. W. Webb, X. L. Wu, C. Xu, Science, 1998, 281, 1653; b) M. Rumi, J. E. Ehrlich, A. A. Heikal, J. W. Perry, S. Barlow, Z. Hu, D. McCord-Maughon, T. C. Parker, H. Röckel, S. Thayumanavan, S. R. Marder, D. Beljonne, J. L. Brédas, J. Am. Chem. Soc., 2000, 122, 9500; c) S. J. K. Pond, M. Rumi, M. D. Levin, T. C. Parker, D. Beljonne, M. W. Day, J.

L. Brédas, S. R. Marder, J. W. Perry, J. Phys. Chem. A, 2002, 106, 11470.

[9] A. Treibs, N. Haeberie, J. Liebigs, Ann. Chem., 1968, 718, 183.

[10] a) Gupta, M. Ravikanth, J. Photochem. Photobiol. A 2006, 177, 156; b) H. Segawa, F.-P. Wu, N. Nakayama, H. Maruyama, S. Sagisaka, N. Higuchi, M. Fujitsuka, T. Shimidzu, Synth. Met. 1995, 71, 2151; c) M. A. Torréns, T. K. Straub, L. M. Epstein, J. Am. Chem. Soc., 1972, 94, 4160; d) P. Bhyrappa, P. Bhavana, Chem. Phys. Lett., 2001, 349, 399.

[11] a) N. Ono, H. Miyagawa, T. Ueta, T. Ogawa, H. Tani, J. Chem. Soc., Perkin Trans. 1, 1998, 1595; b) Zhang, B. He, J. Photochem. Photobiol. A 2005, 172, 283.

[12] P. B. Momo, C. Pavani, M. S. Baptista, T. J. Brocksom, K. T. d. Oiviera, Eur. J. Org. Chem. 2014, 4536.

[13] C. O. Paul-Roth, J. Letessier, S. Juillard, G. Simonneaux, T. Roisnel, J. Rault-Berthelot, J. Mol. Struct., 2008, 872, 105.

[14] J. Rochford, S. Botchway, J. J. McGarvey, A. D. Rooney, M. T. Pryce, J. Phys. Chem., 2008, 112, 11611.

[15] a) J. S. Lindsey, K. A. Maccrum, J. S. Tyhonas, Y. Y. Chuang, J. Org. Chem., 1994, 59, 579; b) F. R. Li, K. X. Yang, J. S. Tyhonas, K. A. Maccrum, J. S. Lindsey, Tetrahedron, 1997, 53, 12339.

[16] K. Sonogashira, Y. Tohda, N. Hagihara, Tetrahedron Lett., 1975, 50, 4467.

[17] a) Borst, M. L. G.; Bulo, R. E.; Gibney, D. J.; Alem, Y.; de Kanter, F. J. J.; Ehlers, A. W.;

Schakel, M.; Lutz, M.; Spek, A. L.; Lammertsma, K. J. Am. Chem. Soc. 2005, 127, 16985; b)

Sahu, B.; Muruganantham, R.; Namboothiri, I. N. N. Eur. J. Org. Chem. 2007, 2477; c)

Polyansky, D. E.; Danilov, E. O.; Voskresensky, S. V.; Rodgers, M. A. J.; Neckers, D. C. J. Am. Chem. Soc. 2005, 127, 13452.

[18] Yao, D.; Zhang, X.; Triadon, A.; Richy, N.; Mongin, O.; Blanchard-Desce, M.; Paul, F.;

Paul-Roth, C. O. Chem. Eur. J. 2017, 23, 2635. 
[19] Triadon, A. ; Paul, F. et al. Organometallics, 2017, in preparation.

[20] Xu, C.; Webb, W. W. J. Opt. Soc. Am. B 1996, 13, 481.

[21] X. Sun, J. Zhang, B. He, J. Photochem. Photobiol. A 2005, 172, 283.

[22] Brückner, P. C. D. Foss, J. O. Sullivan, R. Pelto, M. Zeller, R. R. Birgea, C. Crundwell, Phys. Chem. Chem. Phys. 2006, 8, 2402.

[23] a) S. Drouet, A. Merhi, G. Grelaud, M. P. Cifuentes, M. G. Humphrey, K. Matczyszyn, M. Samoc, L. Toupet, C. O. Paul-Roth, F. Paul, New J. Chem. 2012, 36, 2192; b) S. Drouet, A. Merhi, D. Yao, M. P. Cifuentes, M. G. Humphrey, M. Wielgus, J. Olesiak-Banska, K. Matczyszyn, M. Samoc, F. Paul, C. O. Paul-Roth, Tetrahedron 2012, 68, 10351.

[24] H. S. Nalwa, Adv. Mater., 1993, 5, 341.

[25] J. G. Breitzer, D. D. Dlott, L. K. Iwaki, S. M. Kirkpatrick, T. B. Rauchfuss, J. Phys. Chem. A., 1999, 103, 6930.

[26] A. Mishira, C. Q. Ma, P. Bäuerle, Chem. Rev., 2009, 109, 1141.

[27] Z. H. Chen, X. Y. Zhou, Z. Y. Li, L. H. Niu, J. X. Yi, F. S. Zhang, J. Photochem. Photobiol., A 2011, 64, 218.

[28] N. M. Boyle, J. Rochford, M. T. Pryce, Coord. Chem. Rev., 2010, 254, 77.

[29] a ) Prasath, R., Bhavana, P. J. Heterocycl. Chem. 2012, 49, 1044; b) R. Prasath, P. Bhavana, J. Mol. Struct. 2015, 1094, 73.

[30] S. J. Silvers, A. Tulinsky, J. Am. Chem. Soc. 1967, 89, 3331.

[31] For some example of solid state structures of tetrathienyl derivatives, see: B. Purushothaman, B. Vargheseb, P. Bhyrappa, Acta Cryst. 2001, C57, 252.; Y. Diskin-Posner, S. Balasubramanian, G. K. Patra, I. Goldberg, Acta Cryst., 2001, E57, m346; M. Bellizzi, P. C. D. Foss, R. Pelto, G. Crundwell, C. Brückner, J. B. Updegraff, M. Zeller, A. D. Hunter, Z. Kristallogr. NCS, 2004, 219, 129; R. Prasath, P. Bhavana, S. W. Ng, E. R. T. Tiekink, Acta Cryst., 2012, E68, m471.

[32] R. E. Martin, F. Diederich, Angew. Chem., Int. Ed. Engl. 1999, 38, 1351.

[33] a) P. Prabhu, V. Patravale, J. Biomed. Nanotechnol. 2012, 8, 859; b) J. Bhaumik, A. K. Mittal, A. Banerjee, Y. Chisti, U. C. Banerjee, Nano Res. 2015, 8, 1373; c) J. Schmitt, V. Heitz, A. Sour, F. Bolze, H. Ftouni, J.-F. Nicoud, L. Flamigni, B. Ventura, Angew. Chem. Int. Ed. 2015, $54,169$. 
[34] Perrin, D. D.; Armarego, W. L. F. Purification of Laboratory Chemicals, 3rd edn., Pergamon Press, Oxford, 1988.

[35] a) N. Demas, G. A. Crosby, J. Phys. Chem. 1971 75, 991; b) G. R. Eaton, Pure Appl. Chem. 1988, 60, 1107.

[36] Werts, M. H. V.; Nerambourg, N.; Pélégry, D.; Le Grand, Y.; Blanchard-Desce, M. Photochem. Photobiol. Sci. 2005, 4, 531. 
*Two new meso-tetra(thien-2-yl)porphyrins $\mathbf{3}$ and $\mathbf{4}$ have been obtained and characterized.

*The two-photon absorption (2PA) cross-sections $\left(\sigma_{2}\right)$ of $\mathbf{3}$ and $\mathbf{4}$ were measured by TPEF, revealing strongly enhanced $\sigma_{2}$

*Replacement of the 1,4-phenylene spacer at the periphery of the porphyrin core by a 2,5-thienylene one allows improvement of the 2PA cross-sections

*Porphyrins $\mathbf{3}$ and $\mathbf{4}$ are efficient Two-photon Photosensitizers for Singlet Oxygen Generation 